\title{
Ménétrier disease and gastrointestinal stromal tumors: hyperproliferative disorders of the stomach
}

\author{
Robert J. Coffey, ${ }^{1}$ Mary Kay Washington, ${ }^{2}$ Christopher L. Corless, ${ }^{3}$ and Michael C. Heinrich ${ }^{4}$ \\ ${ }^{1}$ Departments of Medicine and Cell and Developmental Biology and 2Department of Pathology, Vanderbilt University Medical Center and \\ Nashville Veterans Affairs Medical Center, Nashville, Tennessee, USA. ${ }^{3}$ Department of Pathology and ${ }^{4}$ Departments of Medicine and Cell and \\ Developmental Biology, Oregon Health and Science University and Portland Veterans Affairs Medical Center, Portland, Oregon, USA.
}

\begin{abstract}
Ménétrier disease and gastrointestinal stromal tumors (GISTs) are hyperproliferative disorders of the stomach caused by dysregulated receptor tyrosine kinases (RTKs). In Ménétrier disease, overexpression of TGF- $\alpha$, a ligand for the RTK EGFR, results in selective expansion of surface mucous cells in the body and fundus of the stomach. In GISTs, somatic mutations of the genes encoding the RTK KIT (or PDGFRA in a minority of cases) result in constitutive kinase activity and neoplastic transformation of gut pacemaker cells (interstitial cells of Cajal). On the basis of the involvement of these RTKs in the pathogenesis of these disorders, Ménétrier disease patients have been effectively treated with a blocking monoclonal antibody specific for EGFR and GIST patients with KIT and PDGFRA tyrosine kinase inhibitors.
\end{abstract}

\section{Introduction}

Ménétrier disease and gastrointestinal stromal tumors (GISTs) represent 2 distinct gastric hyperproliferative disorders for which clinically beneficial targeted molecular therapeutics have been developed through increased understanding of the molecular mechanisms behind the disease. Table 1 compares and contrasts these 2 diseases and will be referred to throughout this Review. These conditions arise from dysregulation of different progenitor cell populations and highlight the importance of cellular context in the pathogenesis of proliferative disorders. Notably, enhanced signaling through the receptor tyrosine kinase (RTK) EGFR gives rise to Ménétrier disease, whereas somatic mutations of the genes encoding either of the RTKs KIT or PDGFRA result in GISTs. As we discuss here, understanding the underlying biology of these different conditions has led to the development of medical treatments that target the relevant dysregulated RTK. We believe that the development of new therapies to treat these diseases highlights the power of modern biology to rapidly translate scientific knowledge into new medical treatments.

\section{Clinical features}

Ménétrier disease. Ménétrier disease typically involves the fundus and body of the stomach but spares the antrum (Figure 1). This disorder is characterized by expansion of epithelial cells that constitute the surface mucous cell compartment. There are other hyperproliferative disorders of other epithelial cell compartments of the gastric mucosa. These include Zollinger-Ellison syndrome, which is characterized by expansion of the parietal cell mass due to the presence of gastrin-producing tumors, most often arising in the pancreas, and hyperplasia of entero-

Nonstandard abbreviations used: gB, glycoprotein B; GI, gastrointestinal; GIST, GI stromal tumor; HER, human EGF receptor; ICC, interstitial cell of Cajal; MT, metallothionein; MUC, mucin; RTK, receptor tyrosine kinase.

Conflict of interest: M.C. Heinrich and C.L. Corless receive research funding from and consult for Novartis and Pfizer and are on Speakers Bureau Novartis.

Citation for this article: J. Clin. Invest. 117:70-80 (2007). doi:10.1172/JCI30491. chromaffin-like cells in the setting of chronic acid suppression and increased gastrin levels. These entities will not be discussed further here, because their pathogenesis has not been linked to dysregulated RTKs.

Ménétrier disease was first described by Pierre Ménétrier in 1888 (1). It is thought to be a rare acquired disorder of uncertain etiology. Patients present with a unique constellation of signs and symptoms that include abdominal pain, nausea and vomiting, anemia (due to gastric blood loss), hypochlorhydria (due to markedly reduced, if not absent, numbers of parietal cells), and edema of peripheral tissues (due to leakage of protein across the gastric mucosa). There is an increased incidence of thrombotic events throughout the body, possibly due to a decrease in the intravascular volume. An upper endoscopy usually reveals copious amounts of thick mucus and diffusely enlarged folds of the stomach lining (likened by Ménétrier to cerebral convolutions) in the body and fundus with relative sparing of the antrum; the gastric $\mathrm{pH}$ is often alkaline. Although in adults it is a progressive disorder, there is a childhood form of the disease that resolves spontaneously and has been linked to infection with CMV (2). The average age at diagnosis in adults is 55 , and the disease tends to be more common in men than in women. Ménétrier disease is thought to carry an increased risk of gastric cancer, but the magnitude of this risk is uncertain (3-6). Empiric treatment with anticholinergic therapy, octreotide, acid suppression, and prednisone, as well as eradication of Helicobacter pylori, has provided no consistent benefit. Partial or total gastrectomy is often recommended for patients with debilitating disease or for whom there is concern over the development of cancer.

Histologically, enlarged gastric folds in the body and fundus of the stomach of patients with Ménétrier disease show massive expansion of surface mucous cells (histologically referred to as foveolar hyperplasia) with reduced numbers of parietal cells and chief cells. Although parietal cells are relatively preserved in some cases, most cases show decreased numbers of these epithelial cells specialized to secrete gastric acid. The foveolae (small pits) are often tortuous and undergo cystic dilatation (Figure 2). 
Table 1

Comparison of features of Ménétrier disease and GISTs

\begin{tabular}{lll}
\hline & Ménétrier disease & GISTs \\
Gross appearance & Mucosal hypertrophy & Submucosal mass (can have secondary mucosal ulceration) \\
Dysregulated RTK & EGFR (secondary to excess ligand production) & Somatic mutations of KIT and PDGFRA \\
Putative cell of origin & Gastric progenitor cell & Interstitial cell of Cajal \\
Clonality & Polyclonal & Monoclonal \\
Malignant potential & Likely & Yes \\
Mouse model & MT-TGF- $\alpha$ & Germ-line gain-of-function KIT mutations \\
Kinase-directed therapy & Cetuximab & Imatinib (small-molecule inhibitor of KIT and PDGFRA) \\
& (EGFR-specific blocking monoclonal antibody) & Sunitinib (small-molecule inhibitor of KIT and PDGFRA) \\
Etiology & Uncertain; infection with CMV & Somatic mutation \\
& associated with childhood form of disease & \\
\end{tabular}

The diagnosis of Ménétrier disease is difficult to establish with routine endoscopic superficial mucosal "pinch" biopsies; deeper "snare," or full-thickness, biopsies of the gastric mucosa are more informative. Diagnosis requires clinical and morphological correlation with the endoscopic findings, as hyperplastic gastric polyps can exhibit identical histological features in small biopsy samples. The foveolar epithelial cells contain diastaseresistant PAS-positive neutral mucin, as in normal stomach, and only minor changes in the distribution of the mucin proteins (MUC1-MUC7) are reported (7). Inflammation in the lamina propria is modest, although the enlarged folds are subject to erosion and can show superficial ulcers with granulation tissue and an influx of neutrophils into the lamina propria. A patchy accumulation of eosinophils in the lamina propria is an underappreciated feature of Ménétrier disease, and eosinophils are sometimes the predominant inflammatory cell in the lamina propria (8). The muscularis mucosae (the band of smooth muscle separating the mucosa from the submucosa) is thickened and disorganized, with strands of smooth muscle extending into the lamina propria, a finding that may be due to TGF- $\alpha$ overproduction, as well as prolapse of the enlarged folds.

GISTs. GISTs are the most common mesenchymal neoplasm arising in the abdomen (Table 1) (9-11). These tumors were previously classified as smooth muscle tumors, but in recent years it has become clear that they are clinically, pathologically, and molecularly distinct from other tumors and are much more common than previously appreciated. Unlike Ménétrier disease, GISTs can arise throughout the gastrointestinal (GI) tract, but the stomach is the most common site of origin for GISTs, accounting for $50 \%-60 \%$ of these tumors (9-11). The second most common site is the small intestine (25\%-30\%), while smaller numbers of GISTs arise in the rectum (5\%), esophagus (2\%), and other abdominal locations (5\%), including the appendix, gallbladder, pancreas, mesentery, omentum, and retroperitoneum $(12,13)$.

Gastric GISTs have been identified in patients from 8 to 95 years of age. However, the peak age of diagnosis is around 60 in most series of patients studied, with less than $10 \%$ of the tumors discovered before the age of 40 (11). There is a slight male predominance in adult patients, whereas most pediatric GISTs arise in girls. The incidence of GISTs was recently studied by Kindblom and colleagues in a well-defined population of 1.5 million in southern Sweden (12). All diagnosed tumors that were potential GISTs between 1983 and 2000 were reexamined and, on the basis of this study, the annual incidence of GISTs was estimated at 20 cases per million. Using this estimate, the annual incidence in the United States is predicted to be 4,500 cases.

In contrast to Ménétrier disease, GISTs develop as submucosal masses (Table 1 and Figures 1 and 2). Primary gastric GISTs are generally between 2 and $30 \mathrm{~cm}$ in diameter at the time of diagnosis and can cause mass-related symptoms and anemia due to mucosal ulceration. In a study of a very large series of gastric GISTs recently published by Miettinen and colleagues (1,765 cases), $54.4 \%$ of patients presented with symptoms related to GI bleeding (most commonly anemia) (11). A smaller fraction of patients presented with upper abdominal pain (16.8\%), and the percentage of patients with tumor rupture and the need for emergency surgical resection was quite low (1.7\%). GISTs are not uncommonly discovered as an incidental finding during radiologic imaging or as an unrelated condition during endoscopic, surgical, and autopsy procedures (11).

Most GISTs are composed of a fairly uniform population of spindle-shaped cells (70\% of cases) (Figure 2E). However, some GISTs are dominated by epithelioid cells (10\% of cases) or contain a mixture of spindle and epithelioid morphologies (20\%) $(9,13,14)$. Approximately $95 \%$ of gastric GISTs express the RTK KIT (also known as CD117). However, expression of other markers is more variable (for example, $70 \%$ express CD34 and $5 \%$ express desmin) $(9-11,15-17)$. KIT, CD34, and desmin are a useful combination of markers for confirming the diagnosis of GIST in a morphologically typical case, with desmin serving mainly to rule out leiomyosarcoma (a smooth muscle tumor). It should be noted, however, that KIT- GISTs are now well documented in the literature (13-15).

The treatment of choice for localized gastric GISTs is surgical resection. The goal of surgery is complete gross resection without rupturing the tumor, although this might not be possible in all cases. GISTs should be handled carefully to avoid tumor rupture, which can cause complications such as bleeding or tumor spillage. Tumor rupture is associated with a very high risk of intra-abdominal dissemination of tumor cells and subsequent tumor recurrence. In a series of 191 cases of GIST treated at the M.D. Anderson Cancer Center, patients whose complete resection was complicated by tumor rupture had a substantially shorter overall survival than patients who had complete resections without tumor rupture (18-20). Indeed, the survival of patients with tumor rupture was similar to that of patients with incomplete surgical resection (18-20). 


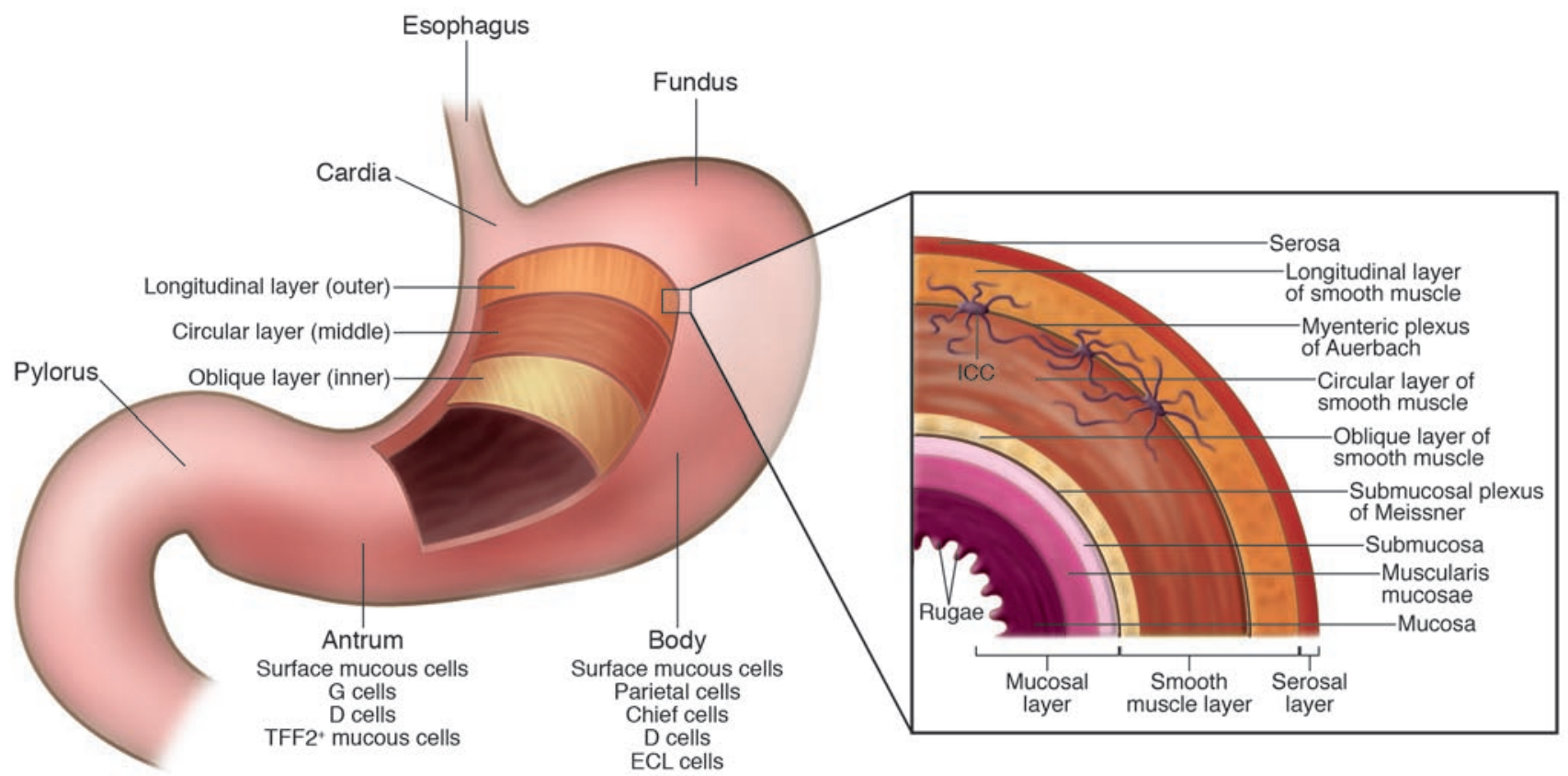

Figure 1

Anatomy of the human stomach. The inset provides more detail of the layers of the stomach wall and indicates the location of the myenteric plexus of Auerbach. Interstitial cells of Cajal (ICCs), which are specialized, spindle-shaped cells located in the gut wall that function as pacemaker cells and help regulate slow-wave peristalsis of the gut, form a network around the myenteric plexus of Auerbach and serve to regulate neural input to the smooth muscle cells of the muscularis propria. The ICC cell bodies lie in close proximity to myenteric nerves, whereas their processes extend deeply into the inner and outer layers of the muscularis, contacting individual myocytes.

Until the year 2000, the only known "effective" treatment for metastatic GISTs was surgery, as chemotherapy and radiation treatments had no proven effective role in the treatment of advanced disease (21). Most patients with such advanced GISTs have both peritoneal and hepatic metastases. Not surprisingly, the historical results of surgery for such patients have been extremely poor - essentially, disease recurs in all patients with a very short disease-free interval $(20,22-24)$.

\section{RTK dysregulation in the pathogenesis of Ménétrier disease and GISTs}

RTKs are transmembrane glycoproteins that are activated by binding of their cognate ligands (25). Ligand binding produces changes in protein conformation, resulting in activation of the cytoplasmic tyrosine kinase domain. The resultant kinase activation results not only in receptor autophosphorylation but also in the phosphorylation of downstream signaling proteins.

All RTKs have a similar structure consisting of a ligand-binding extracellular domain, a single-pass transmembrane domain, and a cytoplasmic domain that possesses tyrosine kinase activity. Different RTKs have unique extracellular protein sequences that contain different types of functional domains (for example, Ig-like domains in KIT and cysteine-rich domains in EGFR), and these confer ligandbinding specificity. By contrast, the cytoplasmic domain is highly conserved among RTKs, with a juxtamembrane domain, a catalytic domain, and a carboxy-terminal region. On the basis of homology of the extracellular and cytoplasmic domains, RTKs can be grouped into families. For instance, EGFR and related RTKs such as human EGF receptor 2 (HER2; also known as ERBB2) are classified as type I RTKs, whereas KIT is classified as a type III $\operatorname{RTK}(25,26)$.
EGFR is a $170-\mathrm{kDa}$ transmembrane glycoprotein that functions as the receptor for 7 mammalian EGFR ligands that bind either exclusively to EGFR (TGF- $\alpha$, EGF, amphiregulin, and epigen) or to EGFR and HER4 (heparin-binding EGF-like growth factor, betacellulin, and epiregulin). Ligand engagement results in receptor dimerization and kinase activation, a prerequisite for all subsequent signaling events (Figure 3A) (27).

$\mathrm{KIT}$ is a $145-\mathrm{kDa}$ transmembrane glycoprotein that functions as the receptor for $\operatorname{SCF}(28,29)$. KIT is closely related to the receptors for PDGF, M-CSF, and FMS-like tyrosine kinase 3 ligand (FLT3L) $(26,30)$. KIT function is critical to the development of the interstitial cells of Cajal (ICCs), as well as hematopoietic progenitor cells, mast cells, and germ cells (30). Binding of homodimeric SCF to KIT results in receptor homodimerization, activation of KIT tyrosine kinase activity, and phosphorylation of various substrates (Figure $3 \mathrm{~B})(28,30)$. In many cases, the substrates are themselves kinases that function as effectors of intracellular signal transduction (26).

Activation of either EGFR or KIT kinase activity results in activation of a multitude of downstream intracellular signaling pathways. Of these pathways, the most important ones seem to be the MAPK pathway and the PI3K-AKT-mTOR pathway (Figure 3). In many human cell types, activation of the MAPK pathway is closely linked to activation of cellular proliferation, whereas activation of the PI3K-AKT-mTOR pathway seems to be more important for avoiding apoptosis. However, there is substantial cross-activation of these pathways, and the biological consequence of pathway activation can depend on cellular context $(25,26)$.

EGFR and Ménétrier disease. Formerly a disorder with an uncertain etiology, Ménétrier disease is now believed to result from 
A

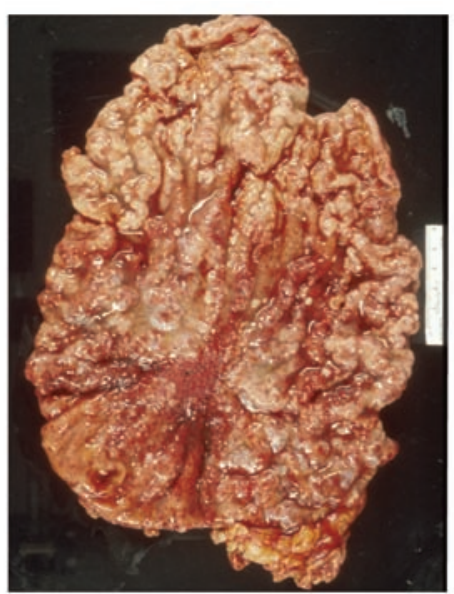

D

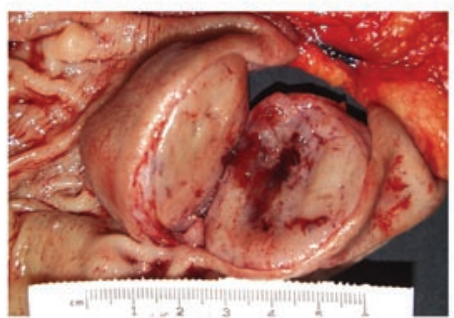

B

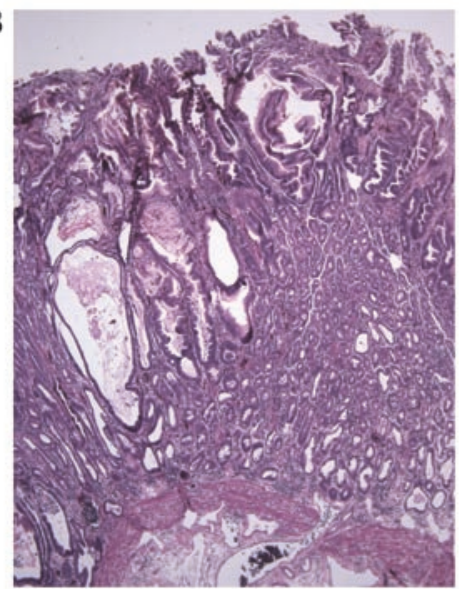

E

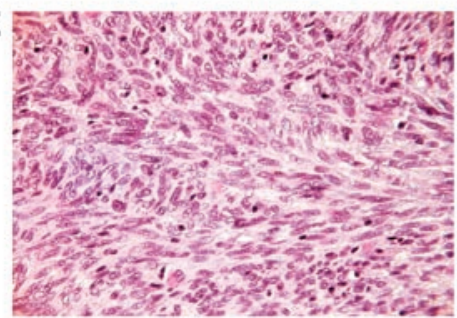

C

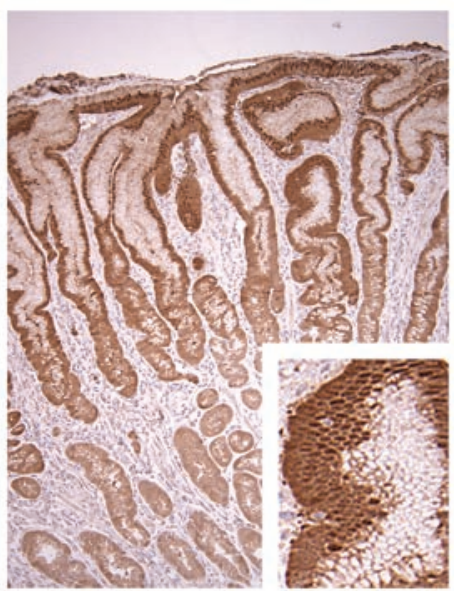

F

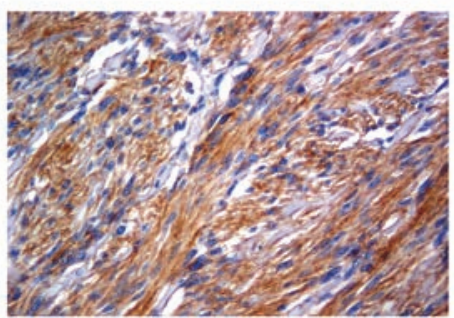

Figure 2

Gross and microscopic view of Ménétrier disease and GIST. (A and B) Gross (A) and microscopic (B) appearance of the stomach of a patient with Ménétrier disease (original magnification of $\mathbf{B}, \times 40$ ). ( $D$ and $E$ ) Gross (D) and microscopic (E) appearance of the stomach of a patient with a submucosal gastric GIST (original magnification of $\mathbf{E}, \times 200$ ). In $\mathbf{D}$, the mucosa is stretched over the submucosal GIST with its typical central degenerative changes. (E) Typical spindle-shaped appearance of a GIST; less common are epithelioid-shaped and mixed epithelioid- and spindle-shaped GISTs. (C) TGF- $\alpha$ immunoreactivity in the gastric mucosa of a Ménétrier disease patient (original magnification, $\times 100$; inset, $\times 300$ ). (F) KIT immunoreactivity in a GIST (original magnification, $\times 200$ ). The rulers in $\mathbf{A}$ and $\mathbf{D}$ are the same scale.

enhanced EGFR signaling in the gastric mucosa due to local overproduction of TGF- $\alpha$ (Table 1). Both TGF- $\alpha$ and EGFR are expressed in the normal gastric mucosa (31), with TGF- $\alpha$ being found predominantly in parietal cells and at the luminal surface of mucous cells in the body and fundus of the stomach. In isolated rabbit parietal cells, pretreatment with TGF- $\alpha$ resulted in a dose-dependent reduction of histamine-stimulated, but not carbachol-stimulated, acid secretion (32). TGF- $\alpha$ has also been shown to stimulate growth of guinea pig gastric mucosal cells (33) and canine fundic epithelial cells (34). Systemic administration of TGF- $\alpha$ protected the gastric mucosa from ethanol- and aspirin-induced gastric injury in rats (35); this cytoprotective effect was temporally linked to a dramatic increase in levels of insoluble gastric mucin. In separate studies, it was shown that sustained transgenic overexpression of TGF- $\alpha$ in the mammary glands of mice resulted in a series of premalignant changes that culminated in mammary adenocarcinoma $(36,37)$.

Collectively, these observations indicate that overproduction of TGF- $\alpha$ in the stomach might contribute to the pathogenesis of Ménétrier disease, which is itself a premalignant hyperproliferative disorder of the stomach (Table 1). Indeed, 15 patients with Ménétrier disease exhibited enhanced immunoreactivity for TGF- $\alpha$ in their expanded surface mucous cell compartment, despite a marked diminution in numbers of parietal cells (38). Moreover, transgenic mice overexpressing rat TGF- $\alpha$ in the stomach (metallothionein-TGF- $\alpha$ [MT-TGF- $\alpha]$ mice) exhibited virtually all the features of Ménétrier disease, including foveolar hyperplasia with increased mucin staining and cystic dilatation, a marked reduction in numbers of chief cells and parietal cells, and reduced basal and histamine-stimulated rates of acid production (39). A similar phenotype was observed in transgenic mice expressing human TGF- $\alpha$ in the stomach (40-42).

It is important to emphasize that the precise underlying molecular defect that results in upregulation of TGF- $\alpha$ in Ménétrier disease is not known and that TGF- $\alpha$ is not overexpressed elsewhere in the bodies of individuals with Ménétrier disease. Although TGF- $\alpha$ immunoreactivity is increased in the expanded surface mucous cell compartment, expression of other EGFR ligands has not been studied. EGFR is not overexpressed in the gastric mucosa of individuals with Ménétrier disease, but a mutational analysis of EGFR in these individuals has not been performed. It is probable that there is host susceptibility to developing Ménétrier disease, with a genetic predisposition toward developing this disorder, as MT-TGF- $\alpha$ mice exhibit a Ménétrier disease phenotype on C57BL/ 6 and FVB backgrounds but no such phenotype on a CD1 background, even though the 2 groups of mice express equivalent levels of TGF- $\alpha(39,42,43)$.

The childhood form of Ménétrier disease has been linked to infection with CMV (2) (Table 1). Clinical features in these cases include substantial edema of peripheral tissues at the time of presentation and spontaneous resolution of the disease over 2-4 weeks. It has been difficult to establish a clear etiological role for CMV in the pathogenesis of Ménétrier disease in children, because infection with CMV is common in children, and CMV 
A

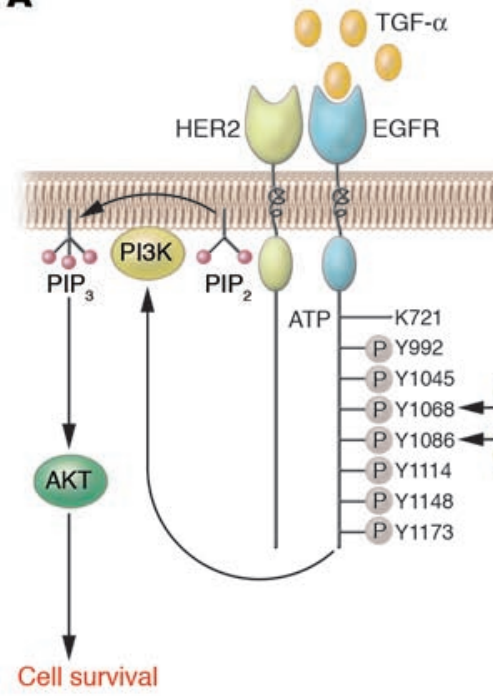

Plasma membrane

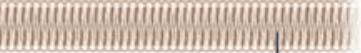

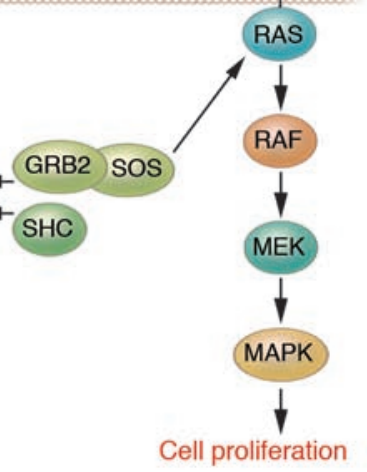

B

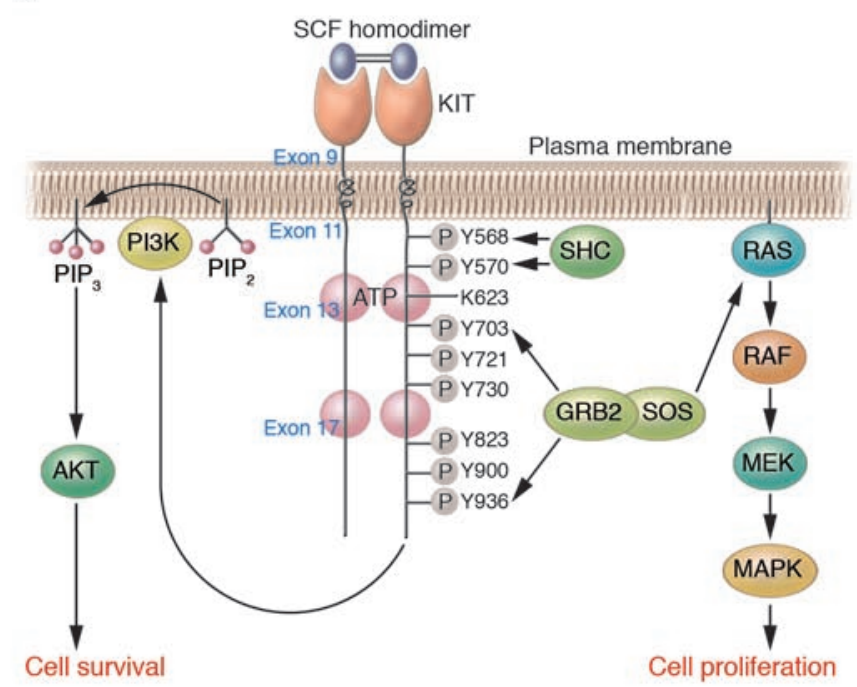

Figure 3

Schematic depiction of EGFR and KIT signaling. (A) Expression of TGF- $\alpha$ is upregulated in the gastric mucosa of patients with Ménétrier disease. Ligand binding results in a conformational change in the ectodomain of the receptor from a tethered intramolecular state to a dimer-competent state (27). Homodimerization and/or heterodimerization with other EGFR family members results in activation of the intrinsic tyrosine kinase that phosphorylates, probably in trans, tyrosine residues $(Y)$ in the cytoplasmic tail. Shown are the 7 autophosphorylation sites in the EGFR cytoplasmic tail. SH2-containing proteins bind these phosphorylated tyrosine residues to initiate a complex signaling cascade. GRB2 and SHC are reported to bind Y1068, Y1086, Y1148, and Y1173 (27). Activation or inhibition of EGFR usually results in coordinate regulation of MAPK and AKT, which are linked to proliferation and cell survival, respectively. (B) SCF is the only known KIT ligand. Binding of homodimeric SCF to KIT results in receptor homodimerization, activation of the intrinsic tyrosine kinase domain, and trans-phosphorylation of cytoplasmic KIT tyrosine residues. Somatic mutation of exon 9, 11, 13, or 17 in GISTs results in constitutive, ligand-independent KIT activation. Depicted are 8 tyrosine autophosphorylation sites in the KIT cytoplasmic domain. SH2-containing proteins bind these phosphorylated tyrosine residues and are then phosphorylated on tyrosine residues by KIT to initiate a complex signaling cascade. Y823 is located in the KIT activation loop; phosphorylation of this residue helps stabilize the activation loop in the "active" state and allows binding of protein substrates to the active site. Activation of KIT results in coordinate regulation of MAPK and AKT (108).

can be a commensal organism in inflamed gastric mucosa. Rarely is there ironclad evidence of acute CMV infection by serology and CMV inclusions in the gastric mucosa (44). It is nevertheless of interest that increased immunohistochemical staining for TGF- $\alpha$ in the involved gastric mucosa has been reported in a childhood case of CMV-associated Ménétrier disease (45). Given the role for EGFR signaling in Ménétrier disease, a recent report that human CMV infects cells by interacting with EGFR and inducing downstream signaling adds biological plausibility to an etiological role for CMV in childhood Ménétrier disease (46). This study (46) provided evidence that the principal envelope glycoprotein of CMV, glycoprotein B (gB), bound EGFR, inducing EGFR-HER3 heterodimers and activating the PI3K-AKT signaling pathway. This finding assumes possible clinical relevance since the $\mathrm{CMV}$ vaccine being tested is composed of $\mathrm{gB}$ (47). Although it is not known whether $\mathrm{gB}$ alone is capable of inducing disease, gB-induced Ménétrier disease should at least be considered in individuals receiving the vaccine who develop upper GI symptoms and edema of their peripheral tissues.

KIT, PDGFRA, and GISTs. Hirota et al. made the seminal observation that activating mutations of KIT exon 11 (which contains the juxtamembrane domain) were present in most GISTs that they analyzed (48). Subsequent studies have identified that KIT exon 11 mutations are indeed the most common GIST-associated kinase mutation and are found in approximately $70 \%$ of GISTs (12). Activating mutations of KIT exon 9 (which forms part of the extracellular domain), exon 13 (which forms one lobe of the kinase domain), and exon 17 (which forms a second lobe of the kinase domain) are found in approximately $10 \%-15 \%, 1 \%$, and $1 \%$ of GISTs, respectively (9) (Table 1).

Several lines of evidence support the hypothesis that activating mutations of KIT are the initiating event in most adult GISTs: first, KIT mutations are common in small, incidentally discovered GISTs; second, KIT mutation status does not correlate with pathological grade; third, germ-line activating KIT mutations are associated with heritable susceptibility to GIST; fourth, expression of mutant KIT in mice results in GISTs; and last, KIT mutations antedate cytogenetic abnormalities (49-53).

KIT mutations, however, are not found in all GISTs. A small subset of GISTs have constitutively activating mutations in the gene encoding PDGFRA, an RTK homologous to KIT, whereas other GISTs lack detectable mutations in either KIT or PDGFRA (54-56). This suggests that GIST oncogenesis is multifactorial and can be triggered by constitutive activity of KIT, PDGFRA, and other unknown molecular targets $(9,50,54,57,58)$. Interestingly, most GISTs with PDGFRA mutations arise in the stomach and manifest an epithelioid, rather than spindle, cell morphology $(11,54,59)$.

Overall, either KIT or PDGFRA mutations are found in $80 \%-90 \%$ of adult GISTs, and these mutations are mutually exclusive (that is, there are no reported cases of both KIT and PDGFRA mutations in the same tumor). The molecular pathogenesis 
of GISTs lacking kinase mutations remains unknown but is the subject of intensive investigation. From the standpoint of light microscopy and immunohistochemistry, these tumors are indistinguishable from GISTs with kinase mutations. However, as noted below, treatment with imatinib (a potent smallmolecule inhibitor of a group of RTKs that includes KIT and PDGFRA, as well as ABL kinases) is less effective for individuals with these tumors than it is for individuals with KIT-mutant GISTs $(9,60,61)$.

Pediatric GISTs represent a distinct clinicopathological entity from adult GISTs. Important differences between these entities include that pediatric GISTs have a strong association with female gender, have a nearly universal gastric origin with multinodular growth, have a high frequency of lymph node metastases (which is rare in adults with a GIST), have a lack of kinase mutations ( $<10 \%$ of cases), have an epithelioid morphology, have a typically slow pace of disease progression, and have a gene expression profile distinct from that of adult GISTs $(59,62)$. The molecular pathogenesis of pediatric GISTs remains obscure but could conceivably be related to some of the mechanisms that give rise to adult GISTs that lack kinase mutations.

\section{Ménétrier disease and GISTs as disorders of progenitor cells}

Ménétrier disease. In the normal body and fundus of the stomach, the region in which progenitor cells are found (known as the progenitor zone) is located at the isthmus (also known as the neck) of the glands, whereas elsewhere in the GI tract the progenitor zone is located at the base of the glands. On the basis of a detailed radioautographic and electron microscopic analysis of the mouse fundus, Karam and Leblond identified the undifferentiated granule-free cell as the fundic stem cell (63-68). It is unlikely that this cell represents a true stem cell, as it exhibited the highest labeling index of the cells studied. Nevertheless, we are indebted to these investigators for describing the 10 lineages to which this cell gives rise (Figure 4A).

Normally, cellular proliferation in the body and fundus of the stomach is restricted to the progenitor zone in the isthmus (Figure 4B). From this region, precursor cells give rise to surface mucous cells that move to the luminal surface of the glands and that have a lifespan of 3-5 days, as well as to parietal cells that move predominantly down to the base of the glands and to mucous neck cells, which also migrate down and further differentiate into chief cells. Parietal cells and chief cells have long lifespans of 54 and 194 days, respectively, as calculated by Karam and Leblond (65). Because of the long lifespan of gland cells, the normal pit cell/gland cell ratio is $1: 4$. This ratio is often reversed in individuals with Ménétrier disease, in whom there are increased numbers of surface mucous cells, and decreased numbers of parietal cells and chief cells (Figure 4B).

From serial analysis of the gastric mucosa of MT-TGF- $\alpha$ transgenic mice using proliferative and lineage-specific markers, we have seen no evidence of increased apoptosis among parietal cells and chief cells (69). Rather, there is a dramatic increase in the number of surface mucous cells with a markedly expanded proliferative compartment that is repositioned down toward the base of the glands. This occurs in the setting of inappropriately normal levels of serum gastrin (Figure 4B). The MT-TGF- $\alpha$ mice and most of the Ménétrier disease patients that we have studied are hypochlorhydric but exhibit relatively normal levels of serum gastrin, a dis- tinctly abnormal finding in that an alkaline gastric $\mathrm{pH}$ is a potent stimulus for gastrin secretion (70). We propose a model in which enhanced EGFR signaling in the presence of an inappropriately normal serum gastrin (known to be trophic for parietal and chief cells) expands and redirects gastric progenitor cells to production of surface mucous cell lineages at the expense of parietal cells and chief cells. In both TGF- $\alpha$-overexpressing transgenic mice and patients with Ménétrier disease, we also see expression of products in the gastric body and fundus that are normally expressed in the antrum. These include pancreatic and duodenal homeobox gene 1 (PDX1), trefoil factor 2 (TFF2), and gastrin (71). Therefore, there also seems to be repatterning of the oxyntic (acid-producing) mucosa toward an antral-gland phenotype.

GISTs. ICCs are specialized, spindle-shaped cells located in the gut wall that function as pacemaker cells and help regulate slow-wave peristalsis of the gut. ICCs form a network around the myenteric plexus and serve to regulate neural input to the smooth muscle cells of the muscularis propria. Inconspicuous on standard H\&E-stained sections, ICCs can be highlighted by immunohistochemistry for KIT, revealing a distinctive, dendritic morphology. The cell bodies lie in close proximity to myenteric nerves, whereas their processes extend deeply into the inner and outer layers of the muscularis propria, contacting individual myocytes (Figure 1) (72-75).

GISTs have features in common with the myenteric plexus subtype of ICCs that are found in the stomach and intestines, including frequent expression of CD34, embryonic smooth muscle myosin heavy chain, the intermediate filament nestin, and PKC- $\theta$ (72-78). Myenteric plexus ICCs fail to develop in mice that lack expression of KIT or its ligand, SCF, indicating that the SCF-KIT axis is essential to the development of these cells $(79,80)$. Conversely, humans (or mice) with germ-line activating mutations of KIT (or Kit) have diffuse polyclonal ICC hyperplasia that gives rise to focal, clonally distinct GISTs (81).

The anatomic distribution of kinase mutations and GIST tumors suggests that different regions of the gut contain populations of ICC that vary in their kinase dependency and/or underlying biology. For example, $98 \%$ of GISTs with KIT exon 9 mutations arise in the small or large intestine, whereas $98 \%$ of GISTs with PDGFRA mutations arise in the stomach (9). In addition, both the type of kinase mutation and the anatomic site of origin influence the gene expression profile of GISTs $(82,83)$. These observations are further supported by 2 different mouse models of GIST one with a knock-in of an activating Kit exon 11 mutation and the other with an activating Kit exon 13 mutation $(52,53)$. Both models are characterized by diffuse hyperplasia of ICCs from the distal esophagus to the proximal duodenum, as well as in the colon and rectum, but no hyperplasia of ICCs in the small intestine $(52,53)$. Therefore, there is geographic variation in the sensitivity of mouse ICCs to Kit mutations.

\section{Molecular therapy of Ménétrier disease and GISTs}

Ménétrier disease. The evidence supporting Ménétrier disease as a disorder of excess EGFR signaling led the United States FDA to approve a compassionate-use study of a month-long course of cetuximab (a monoclonal antibody that blocks ligand binding to the EGFR) for a 48-year-old man with Ménétrier disease who exhibited unremitting nausea and vomiting, edema to his waist, and hypoalbuminemia (Table 1). The patient was not considered for gastrectomy because of the risk associated with anesthesia and surgery as a result of an underlying chronic disorder - primary 


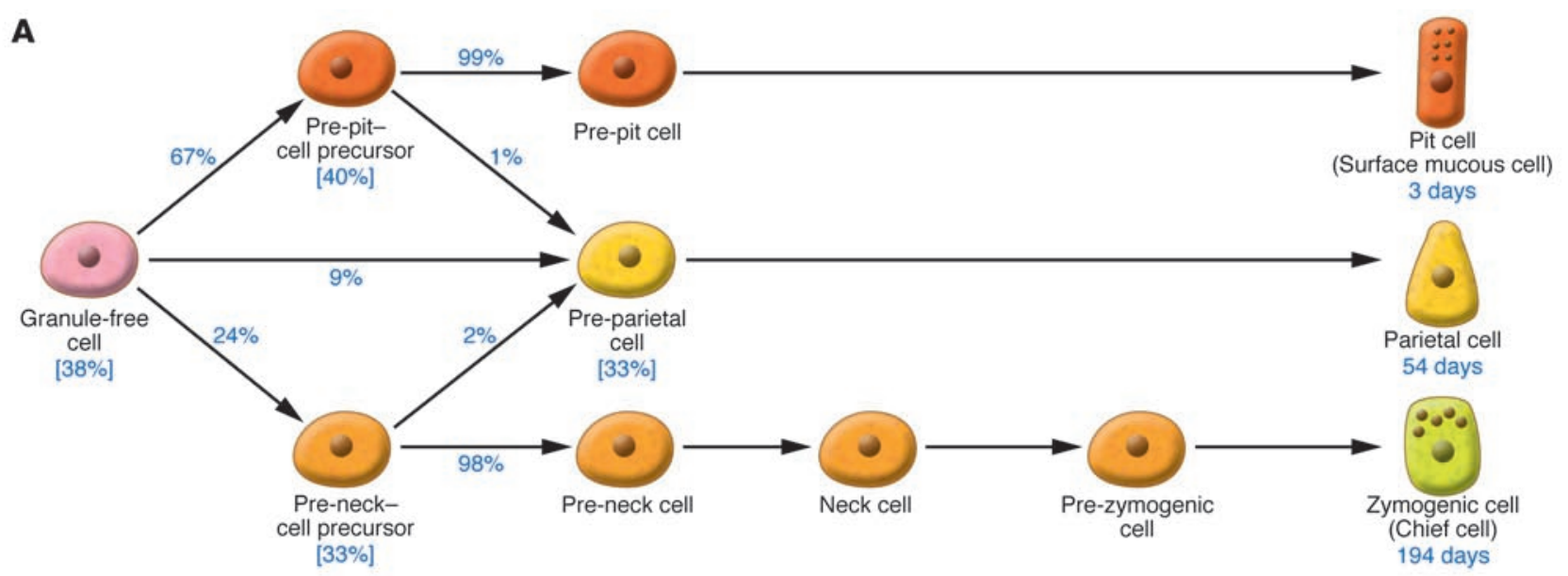

B
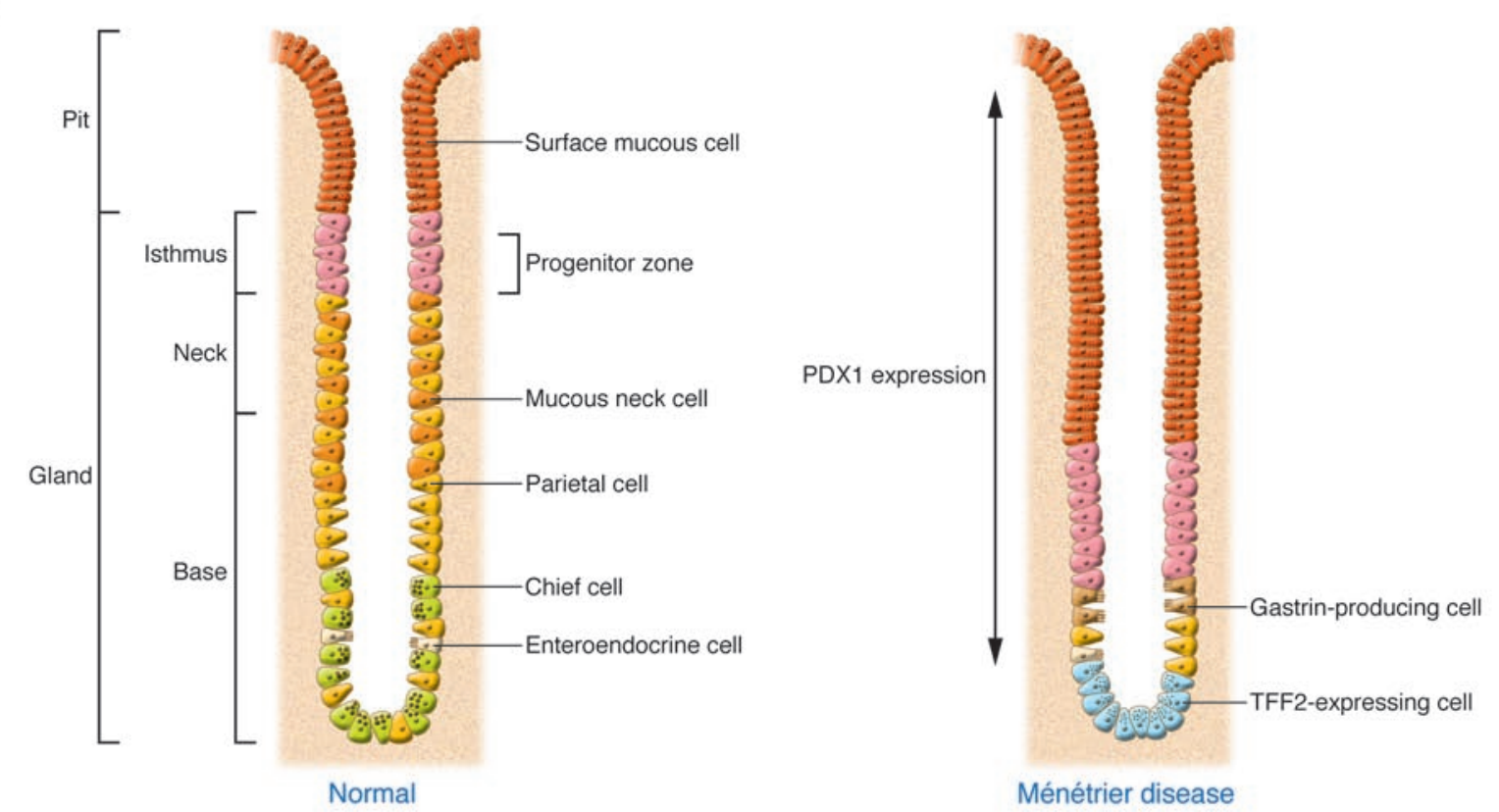

Figure 4

Ontogeny of cell lineages in the normal gastric body and proposed model for the pathogenesis of Ménétrier disease. (A) In the isthmus, the stationary undifferentiated granule-free cell gives rise to pit and gland precursor cells that migrate and ultimately mature into surface mucous cells, parietal cells, and chief cells. The percentage of cells estimated to follow each differentiation pathway is indicated. The numbers in brackets indicate percentages of these progenitor cells that were found by Karam and Leblond to be proliferating; it was calculated that there was an approximately 3-day turnover time (the time required to replace the number of cells equal to the entire population) for these 4 cell types (65). Lifespans of surface mucous cells, parietal cells, and chief cells have been calculated to be 3 days, 54 days, and 194 days, respectively (65). Enteroendocrine cells also were thought by these investigators to emerge from the granule-free cell. (B) In Ménétrier disease, the progenitor compartment is expanded and repositioned at the base of the gland. We propose that this is due to increased signaling through EGFR and decreased levels of gastrin. There is expansion of the surface mucous cell compartment at the expense of parietal cells and chief cells. PDX1, pancreatic and duodenal homeobox gene 1; TFF2, trefoil factor 2.

pulmonary hypertension. After 1 day of treatment with cetuximab, the patient's nausea and vomiting markedly decreased, and after 1 month, there was dramatic clinical and biochemical improvement, including an increase in the serum albumin concentration, a decrease in the loss of protein in the stool, and the appearance of gastric parietal cells (84).

In addition to providing clinical proof of concept, correlative studies using this patient's specimens allowed us to further test our hypothesis concerning dysregulated EGFR activation and derangement of gastric mucosal cell differentiation in the pathogenesis of this disorder (84). Twenty-four hours after the initial dose of cetuximab, there was a dramatic decrease in proliferation in the involved gastric mucosa, as determined by a marked reduction in both active phosphorylated MAPK and the number of Ki67 $7^{+}$cells per glandular unit. Pretreatment serum gastrin was 82 ( $<100$ being normal), despite a gastric $\mathrm{pH}$ of 7 . Serum gastrin increased to $425 \mathrm{pg} / \mathrm{ml} 1$ day after the start of treatment and remained high $(591 \mathrm{pg} / \mathrm{ml}) 1$ month later. In contrast to 
decreased phosphorylated MAPK, there was increased total and phosphorylated AKT; however, this signal emanated from the emergent parietal cell population. After 1 month, there was a shift in the proliferative zone from the base upward toward a more normal location. These results are consistent with our model, which will be more rigorously tested in the analysis of additional patient samples to be collected in the context of an expanded clinical study (see below). The altered levels of serum gastrin generated by blockade of the EGFR suggest that there is likely to be local interplay between TGF- $\alpha$, gastrin, and somatostatin in the stomach.

On the basis of this successful intervention, we have instituted a clinical trial using cetuximab to treat 10 Ménétrier disease patients with disease-related refractory symptoms who are considering gastrectomy as the remaining therapeutic option. To date, we have treated 5 patients, and all of them have exhibited marked clinical and biochemical improvement. One patient experienced no cetuximab-associated rash but clearly benefited from the drug. We recently reported results from the chronic treatment of 2 of these patients (85).

GISTs. In the case of GISTs, in the late 1990s a number of investigators hypothesized that KIT mutations were the initiating event in most GISTs and served to support the proliferation and survival of advanced GISTs (48). This hypothesis provided a rationale for the preclinical study of the small-molecule KIT inhibitor imatinib for treatment of GISTs $(86,87)$. On the basis, in part, of these studies, imatinib was tested for treatment of advanced, unresectable GISTs (88-90). It should be noted that, like in the case of Ménétrier disease, imatinib was originally tested in a single-patient proofof-concept study - the positive results from this patient were the impetus for the further clinical investigation of imatinib for treatment of advanced GISTs (Table 1).

Imatinib reliably achieves disease control in $70 \%-85 \%$ of patients with advanced $\mathrm{KIT}^{+}$GISTs, and the median progression-free survival is 20-24 months (90-92). Even more impressively, the estimated median overall survival time after initiation of imatinib therapy exceeds 36 months in all of the larger clinical studies performed to date $(61,92,93)$. These results are superior to historical data on either surgery or chemotherapy for the treatment of advanced GISTs. For example, in a large series of patients with advanced GISTs treated with front-line doxorubicin-based chemotherapy, the median survival was only 9 months $(20-22,92)$.

In all of the above studies, imatinib at doses of $400-800 \mathrm{mg} / \mathrm{d}$ proved to be efficacious, well tolerated, and safe. On the basis of the results of a US-Finnish phase II GIST study and the clinical studies of imatinib for treatment of chronic myelogenous leukemia, imatinib was approved by the FDA for the treatment of unresectable and metastatic GISTs on February 1, 2002. Several excellent reviews provide additional details on the use of imatinib in the clinical management of GISTs (91, 94-96).

In several studies, the likelihood of an objective clinical response to imatinib correlated with the underlying tumor genotype, with the highest response rates being seen in patients whose tumor had a KIT exon 11 mutation $(60,61,97)$. Patients with GISTs that expressed an exon 11 mutant isoform of KIT also had a longer median time to treatment failure and longer overall survival. By contrast, GISTs with no KIT mutation or with the PDGFRA D842V mutation were less likely to have favorable or durable responses to treatment with imatinib $(60,61,97)$. More recently, Debiec-
Rychter et al. have reported that patients whose GISTs harbor KIT exon 9 mutations have markedly improved progression-free survival when treated with $800 \mathrm{mg} / \mathrm{d}$ of imatinib, compared with the standard dose of $400 \mathrm{mg} / \mathrm{d}$ (60).

Despite the dramatic efficacy of imatinib for treating advanced GISTs, most patients experience tumor progression (as the tumor becomes resistant to imatinib with a median time to progression of approximately 20 months) $(88,90,92)$. Imatinib resistance in GISTs can be divided into 2 broad categories - primary resistance (progression within the first 180 days after initiation of treatment) and secondary resistance. The molecular mechanisms underlying primary resistance are poorly understood. However, GISTs with PDGFRA D842V mutations, with KIT exon 9 mutations, or with no KIT or PDGFRA mutations are overrepresented in this group $(60,61,97,98)$. By contrast, GISTs with secondary imatinib resistance typically acquire kinase mutations in either the drug/ATP-binding pocket (for example, KIT exons 13 and $14)$ or the kinase activation loop (KIT exon 17) that confer in vitro imatinib resistance (98-101). GIST cell lines with secondary kinase mutations of KIT remain dependent on KIT signaling and will undergo cell cycle arrest and/or apoptosis when KIT signaling is inhibited by downregulation of KIT expression or inhibition of KIT kinase activity by alternative small-molecule inhibitors such as sunitinib $(98,102,103)$. The clinical efficacy of sunitinib for the treatment of imatinib-resistant GISTs has been demonstrated in a placebo-controlled, double-blind phase III study (104). The results of this study were the basis for the recent FDA approval of sunitinib for treatment of patients with imatinib intolerance and those who experienced tumor progression during imatinib therapy.

\section{Future directions}

Despite the clinical benefit provided by pharmacological blockade of the EGFR, many questions related to the cause and treatment of Ménétrier disease remain. Is Ménétrier disease one disorder or a spectrum of disorders? What is the underlying molecular defect? Are there activating mutations in EGFR? Do EGFR ligands other than TGF- $\alpha$ contribute to the disease phenotype? This analysis might be relevant since there is auto- and cross-induction of the EGFR ligands $(105,106)$. What role does CMV have in the pathogenesis of Ménétrier disease? Is there a therapeutic role for smallmolecule EGFR tyrosine kinase inhibitors and selective inhibitors of TNF- $\alpha$-converting enzyme (also known as ADAM17), which cleaves transmembrane pro-TGF- $\alpha$ at the cell surface to release the mature soluble ligand that binds and activates EGFR? These agents individually, and in combination, are being tested in patients with a number of solid tumors and might have clinical benefit in the treatment of patients with Ménétrier disease. Will pharmacological blockade of the EGFR completely reverse the disease process, and, if so, will the disease stay in remission after discontinuation of treatment? Another unresolved question is whether inhibition of EGFR signaling might reduce the risk of gastric cancer associated with the disease.

Despite the dramatic improvement in survival that imatinib treatment provides to patients with an advanced GIST, there is no clear evidence that any of these patients are cured by medical treatment alone. As surgery is the only proven curative treatment in this disease, it is rational to speculate that combining surgery with imatinib treatment might improve the cure rate for patients presenting with primary GISTs. A number of organizations are 
conducting studies of adjuvant and/or neoadjuvant imatinib with the goal of answering the following questions: Does the combination of surgery and imatinib increase the cure rate? If so, which group of patients benefits from combined treatment? What is the optimal timing of imatinib treatment in relation to surgery? What are the optimal dose and duration of imatinib treatment? Another major challenge in this field is to develop new treatments for patients with resistance to first- and second-line kinase inhibitors. Not surprisingly, the median time to progression on second-line sunitinib is much shorter than that on front-line imatinib treatment (104). Therefore, there is a growing population of patients in whom both drugs have failed who are in need of other medical treatments. There are a large number of studies being conducted for treatment of refractory GIST; these studies are examining the efficacy of novel KIT inhibitors and/or inhibitors of downstream targets (for example, inhibitors of the PI3K-AKT-mTOR signaling pathway). Ultimately, front-line combination therapy might prove to be the optimal medical strategy, but this hypothesis has yet to be tested in the clinic. Finally, it is hoped that identification of the pathogenetic mechanisms underlying the development of adult and pediatric GISTs with no KIT or PDGFRA mutations will lead to the development of more effective treatments for this subset of GIST patients. We speculate that these mechanisms will also have relevance for the treatment of adults with kinase-mutant GISTs.

In conclusion, we note that Ménétrier disease and GISTs are both rare diseases. In the United States, a rare disease is defined as one that affects less than 200,000 individuals (http://www.rarediseases.org). By this definition, there are 6,000 rare diseases in this country and more than 25 million Americans affected. We submit that the study of these 2 rare disorders, Ménétrier disease and GISTs, has provided insights into disease pathogenesis and has led to effective treatments based on that understanding. Finally, we are reminded what William Harvey wrote in a letter to a Dutch physician 2 weeks before his death in 1657 (107):

"Nature is nowhere accustomed more openly to display her secret mysteries than in cases where she shows traces of her workings apart from the beaten path; nor is there any better way to advance the proper practice of medicine than to give our minds to the discovery of the usual law of Nature, by careful investigation of rarer forms of disease."

\section{Acknowledgments}

R.J. Coffey acknowledges the generous support of ImClone Systems Inc. for providing Cetuximab, the Peter Powell Foundation, and grants from the National Cancer Institute (CA46413), the GI Special Program of Research Excellence (SPORE; P50 CA95103), and the Mouse Models of Human Cancers Consortium (MMHCC; U01 084239). The work was also supported by funding from a Veterans Affairs Merit Review Grant (to M.C. Heinrich) and from the Life Raft Group Research Fund (to M.C. Heinrich and C.L. Corless). The authors thank James R. Goldenring, Robert Jensen, Mitchell Schubert, Mark Schleiss, and John Williams for thoughtful discussions.

Address correspondence to: Robert J. Coffey, Suite 4140 MRB III, 465 21st Avenue South, Vanderbilt University, Nashville, Tennessee 37232, USA. Phone: (615) 343-6228; Fax: (615) 343-1591; E-mail: robert.coffey@vanderbilt.edu.
1. Ménétrier, P. 1888. Des polyadenomes gastriques et leur rapport avec le cancer de l'estomac. Arch. Physiol. Norm. Pathol. 1:32-55; 236-262.

2. Occena, R.O., Taylor, S.F., Robinson, C.C., and Sokol, R.J. 1993. Association of cytomegalovirus with Ménétrier's disease in childhood: report of two new cases with a review of literature. J. Pediatr. Gastroenterol. Nutr. 17:217-224.

3. Mosnier, J.F., et al. 1991. Hypertrophic gastropathy with gastric adenocarcinoma: Ménétrier's disease and lymphocytic gastritis? Gut. 32:1565-1567.

4. Scharschmidt, B.F. 1977. The natural history of hypertrophic gastrophy (Ménétrier's disease). Report of a case with 16 year follow-up and review of 120 cases from the literature. Am. J. Med. 63:644-652.

5. Vandenborre, K.M., et al. 1998. Hypertrophic lymphocytic gastritis with a gastric carcinoma. Eur. J. Gastroenterol. Hepatol. 10:797-801.

6. Wood, M.G., Bates, C., Brown, R.C., and Losowsky, M.S. 1983. Intramucosal carcinoma of the gastric antrum complicating Ménétrier's disease. J. Clin. Pathol. 36:1071-1075.

7. Mall, A.S., Taylor, K., Barnard, R., Dent, D.M., and Kahn, D. 2003. Expression of gastric mucin in the stomachs of two patients with Ménétrier's disease: an immunohistochemical study. J. Gastroenterol. Hepatol. 18:876-879.

8. Wolfsen, H.C., Carpenter, H.A., and Talley, N.J. 1993. Ménétrier's disease: a form of hypertrophic gastropathy or gastritis? Gastroenterology. 104:1310-1319.

9. Corless, C.L., Fletcher, J.A., and Heinrich, M.C. 2004. Biology of gastrointestinal stromal tumors. J. Clin. Oncol. 22:3813-3825.

10. Miettinen, M., and Lasota, J. 2001. Gastrointestinal stromal tumors: definition, clinical, histological, immunohistochemical, and molecular genetic features and differential diagnosis. Virchows.
Arch. 438:1-12.

11. Miettinen, M., Sobin, L.H., and Lasota, J. 2005. Gastrointestinal stromal tumors of the stomach: a clinicopathologic, immunohistochemical, and molecular genetic study of 1765 cases with longterm follow-up. Am. J. Surg. Pathol. 29:52-68.

12. Nilsson, B., et al. 2005. Gastrointestinal stromal tumors: the incidence, prevalence, clinical course, and prognostication in the preimatinib mesylate era - a population-based study in western Sweden. Cancer. 103:821-829.

13. Debiec-Rychter, M., et al. 2004. Gastrointestinal stromal tumours (GISTs) negative for KIT (CD117 antigen) immunoreactivity. J. Pathol. 202:430-438.

14. Medeiros, F., et al. 2004. KIT-negative gastrointestinal stromal tumors: proof of concept and therapeutic implications. Am. J. Surg. Pathol. 28:889-894.

15. Sakurai, S., et al. 2004. Myxoid epithelioid gastrointestinal stromal tumor (GIST) with mast cell infiltrations: a subtype of GIST with mutations of platelet-derived growth factor receptor alpha gene. Hum. Pathol. 35:1223-1230.

16. Fujimoto, Y., Nakanishi, Y., Yoshimura, K., and Shimoda, T. 2003. Clinicopathologic study of primary malignant gastrointestinal stromal tumor of the stomach, with special reference to prognostic factors: analysis of results in 140 surgically resected patients. Gastric Cancer. 6:39-48.

17. Miettinen, M., et al. 2003. Gastrointestinal stromal tumors, intramural leiomyomas, and leiomyosarcomas in the duodenum: a clinicopathologic, immunohistochemical, and molecular genetic study of 167 cases. Am. J. Surg. Pathol. 27:625-641.

18. Mochizuki, Y., et al. 2004. Treatment and risk factors for recurrence after curative resection of gastrointestinal stromal tumors of the stomach. World J. Surg. 28:870-875.

19. Demetri, G.D., et al. 2004. NCCN Task Force Report. Optimal management of patients with gastrointestinal stromal tumor (GIST): expansion and update of NCCN Clinical Practice Guidelines. J. Natl. Compr. Canc. Netw. 2(Suppl. 21):S1-S26.

20. Ng, E.H., Pollock, R.E., Munsell, M.F., Atkinson, E.N., and Romsdahl, M.M. 1992. Prognostic factors influencing survival in gastrointestinal leiomyosarcomas. Implications for surgical management and staging. Ann. Surg. 215:68-77.

21. Dematteo, R.P., Heinrich, M.C., El-Rifai, W.M., and Demetri, G. 2002. Clinical management of gastrointestinal stromal tumors: before and after STI-571. Hum. Pathol. 33:466-477.

22. DeMatteo, R.P., et al. 2000. Two hundred gastrointestinal stromal tumors: recurrence patterns and prognostic factors for survival. Ann. Surg. 231:51-58.

23. Ng, E.H., Pollock, R.E., and Romsdahl, M.M. 1992. Prognostic implications of patterns of failure for gastrointestinal leiomyosarcomas. Cancer. 69:1334-1341.

24. Shiu, M.H., Farr, G.H., Papachristou, D.N., and Hajdu, S.I. 1982. Myosarcomas of the stomach: natural history, prognostic factors and management. Cancer. 49:177-187.

25. Hubbard, S.R., and Till, J.H. 2000. Protein tyrosine kinase structure and function. Annu. Rev. Biochem. 69:373-398.

26. Blume-Jensen, P., and Hunter, T. 2001. Oncogenic kinase signalling. Nature. 411:355-365.

27. Linggi, B., and Carpenter, G. 2006. ErbB receptors: new insights on mechanisms and biology. Trends Cell Biol. 16:649-656.

28. Blume-Jensen, P., et al. 1991. Activation of the human c-kit product by ligand-induced dimerization mediates circular actin reorganization and chemotaxis. EMBO J. 10:4121-4128.

29. Turner, A.M., et al. 1992. Nonhematopoietic tumor cell lines express stem cell factor and display c-kit receptors. Blood. 80:374-381. 
30. Huang, E., et al. 1990. The hematopoietic growth factor $\mathrm{KL}$ is encoded by the Sl locus and is the ligand of the c-kit receptor, the gene product of the W locus. Cell. 63:225-233.

31. Beauchamp, R.D., Barnard, J.A., McCutchen, C.M., Cherner, J.A., and Coffey, R.J., Jr. 1989. Localization of transforming growth factor $\alpha$ and its receptor in gastric mucosal cells. Implications for a regulatory role in acid secretion and mucosal renewal. J. Clin. Invest. 84:1017-1023.

32. Lewis, J.J., Goldenring, J.R., Modlin, I.M., and Coffey, R.J. 1990. Inhibition of parietal cell $\mathrm{H}+$ secretion by transforming growth factor alpha: a possible autocrine regulatory mechanism. Surgery. 108:220-226; discussion 226-227.

33. Rutten, M.J., Dempsey, P.J., Solomon, T.E., and Coffey, R.J., Jr. 1993. TGF-alpha is a potent mitogen for primary cultures of guinea pig gastric mucous epithelial cells. Am. J. Physiol. 265:G361-G369.

34. Chen, M.C., Lee, A.T., and Soll, A.H. 1991. Mitogenic response of canine fundic epithelial cells in short-term culture to transforming growth factor $\alpha$ and insulinlike growth factor I. J. Clin. Invest. 87:1716-1723

35. Romano, M., et al. 1992. Transforming growth factor $\alpha$ protection against drug-induced injury to the rat gastric mucosa in vivo. J. Clin. Invest. 90:2409-2421.

36. Coffey, R.J., Jr., et al. 1994. Acceleration of mammary neoplasia in transforming growth factor alpha transgenic mice by 7,12-dimethylbenzanthracene. Cancer Res. 54:1678-1683.

37. Matsui, Y., Halter, S.A., Holt, J.T., Hogan, B.L., and Coffey, R.J. 1990. Development of mammary hyperplasia and neoplasia in MMTV-TGF alpha transgenic mice. Cell. 61:1147-1155.

38. Bluth, R.F., Carpenter, H.A., Pittelkow, M.R., Page, D.L., and Coffey, R.J. 1995. Immunolocalization of transforming growth factor-alpha in normal and diseased human gastric mucosa. Hum. Pathol. 26:1333-1340.

39. Dempsey, P.J., et al. 1992. Possible role of transforming growth factor alpha in the pathogenesis of Ménétrier's disease: supportive evidence form humans and transgenic mice. Gastroenterology. 103:1950-1963.

40. Bockman, D.E., Sharp, R., and Merlino, G. 1995. Regulation of terminal differentiation of zymogenic cells by transforming growth factor alpha in transgenic mice. Gastroenterology. 108:447-454.

41. Sharp, R., et al. 1995. Transforming growth factor alpha disrupts the normal program of cellular differentiation in the gastric mucosa of transgenic mice. Development. 121:149-161.

42. Takeda, T., et al. 2006. Role of vascular endothelial growth factor in protein loss of Ménétrier's disease. Int. J. Mol. Med. 18:571-576.

43. Kosone, T., et al. 2006. Integrative roles of transforming growth factor-alpha in the cytoprotection mechanisms of gastric mucosal injury. BMC Gastroenterol. 6:22.

44. Eisenstat, D.D., Griffiths, A.M., Cutz, E., Petric, M., and Drumm, B. 1995. Acute cytomegalovirus infection in a child with Ménétrier's disease. Gastroenterology. 109:592-595.

45. Sferra, T.J., Pawel, B.R., Qualman, S.J., and Li, B.U. 1996. Ménétrier disease of childhood: role of cytomegalovirus and transforming growth factor alpha. J. Pediatr. 128:213-219.

46. Wang, X., Huong, S.-M., Chiu, M.L., Raab-Traub, N., and Huang, E.-S. 2003. Epidermal growth factor receptor is a cellular receptor for human cytomegalovirus. Nature. 424:456-461.

47. Schleiss, M.R., and Heineman, T.C. 2005. Progress toward an elusive goal: current status of cytomegalovirus vaccines. Expert Rev. Vaccines. 4:381-406.

48. Hirota, S., et al. 1998. Gain-of-function mutations of c-kit in human gastrointestinal stromal tumors.
Science. 279:577-580.

49. Corless, C.L., McGreevey, L., Haley, A., Town, A., and Heinrich, M.C. 2002. KIT mutations are common in incidental gastrointestinal stromal tumors one centimeter or less in size. Am. J. Pathol. 160:1567-1572.

50. Heinrich, M.C., Rubin, B.P., Longley, B.J., and Fletcher, J.A. 2002. Biology and genetic aspects of gastrointestinal stromal tumors: KIT activation and cytogenetic alterations. Hum. Pathol. 33:484-495.

51. Li, F.P., et al. 2005. Familial gastrointestinal stromal tumor syndrome: phenotypic and molecular features in a kindred. J. Clin. Oncol. 23:2735-2743.

52. Rubin, B.P., et al. 2005. A knock-in mouse model of gastrointestinal stromal tumor harboring kit K641E. Cancer Res. 65:6631-6639.

53. Sommer, G., et al. 2003. Gastrointestinal stromal tumors in a mouse model by targeted mutation of the Kit receptor tyrosine kinase. Proc. Natl. Acad. Sci. U. S. A. 100:6706-6711.

54. Corless, C.L., et al. 2005. PDGFRA mutations in gastrointestinal stromal tumors: frequency, spectrum and in vitro sensitivity to imatinib. J. Clin. Oncol. 23:5357-5364.

55. Heinrich, M.C., et al. 2003. PDGFRA activating mutations in gastrointestinal stromal tumors. Science. 299:708-710.

56. Hirota, S., et al. 2003. Gain-of-function mutations of platelet-derived growth factor receptor alpha gene in gastrointestinal stromal tumors. Gastroenterology. 125:660-667.

57. Lux, M.L., et al. 2000. KIT extracellular and kinase domain mutations in gastrointestinal stromal tumors. Am. J. Pathol. 156:791-795.

58. Rubin, B.P., et al. 2001. KIT activation is a ubiquitous feature of gastrointestinal stromal tumors. Cancer Res. 61:8118-8121.

59. Miettinen, M., Lasota, J., and Sobin, L.H. 2005. Gastrointestinal stromal tumors of the stomach in children and young adults: a clinicopathologic, immunohistochemical, and molecular genetic study of 44 cases with long-term followup and review of the literature. Am. J. Surg. Pathol. 29:1373-1381.

60. Debiec-Rychter, M., et al. 2006. KIT mutations and dose selection for imatinib in patients with advanced gastrointestinal stromal tumours. Eur. J. Cancer. 42:1093-1103.

61. Heinrich, M.C., et al. 2003. Kinase mutations and imatinib response in patients with metastatic gastrointestinal stromal tumor. J. Clin. Oncol. 21:4342-4349.

62. Prakash, S., et al. 2005. Gastrointestinal stromal tumors in children and young adults: a clinicopathologic, molecular, and genomic study of 15 cases and review of the literature. J. Pediatr. Hematol. Oncol. 27:179-187.

63. Gordon, J.I., and Hermiston, M.L. 1994. Differentiation and self-renewal in the mouse gastrointestinal epithelium. Curr. Opin. Cell Biol. 6:795-803.

64. Karam, S.M. 1993. Dynamics of epithelial cells in the corpus of the mouse stomach. IV. Bidirectional migration of parietal cells ending in their gradual degeneration and loss. Anat. Rec. 236:314-332.

65. Karam, S.M., and Leblond, C.P. 1993. Dynamics of epithelial cells in the corpus of the mouse stomach. I. Identification of proliferative cell types and pinpointing of the stem cell. Anat. Rec. 236:259-279.

66. Karam, S.M., and Leblond, C.P. 1993. Dynamics of epithelial cells in the corpus of the mouse stomach. II. Outward migration of pit cells. Anat. Rec. 236:280-296.

67. Karam, S.M., and Leblond, C.P. 1993. Dynamics of epithelial cells in the corpus of the mouse stomach. III. Inward migration of neck cells followed by progressive transformation into zymogenic cells. Anat. Rec. 236:297-313.

68. Karam, S.M., and Leblond, C.P. 1993. Dynamics of epithelial cells in the corpus of the mouse stomach. V. Behavior of entero-endocrine and caveolated cells: general conclusions on cell kinetics in the oxyntic epithelium. Anat. Rec. 236:333-340.

69. Goldenring, J.R., et al. 1996. Overexpression of transforming growth factor-alpha alters differentiation of gastric cell lineages. Dig. Dis. Sci. 41:773-784.

70. Johnson, L.R. 1976. The trophic action of gastrointestinal hormones. Gastroenterology. 70:278-288.

71. Nomura, S., et al. 2005. Evidence for repatterning of the gastric fundic epithelium associated with Ménétrier's disease and TGFalpha overexpression. Gastroenterology. 128:1292-1305.

72. Poole, D.P., Van Nguyen, T., Kawai, M., and Furness, J.B. 2004. Protein kinases expressed by interstitial cells of Cajal. Histochem. Cell Biol. 121:21-30.

73. Robinson, T.L., et al. 2000. Gastrointestinal stromal tumors may originate from a subset of CD34positive interstitial cells of Cajal. Am. J. Pathol. 156:1157-1163.

74. Sakurai, S., Fukasawa, T., Chong, J.M., Tanaka, A., and Fukayama, M. 1999. Embryonic form of smooth muscle myosin heavy chain (SMemb/ MHC-B) in gastrointestinal stromal tumor and interstitial cells of Cajal. Am. J. Pathol. 154:23-28.

75. Sarlomo-Rikala, M., Tsujimura, T., Lendahl, U., and Miettinen, M. 2002. Patterns of nestin and other intermediate filament expression distinguish between gastrointestinal stromal tumors, leiomyomas and schwannomas. APMIS. 110:499-507.

76. Duensing, A., et al. 2004. Protein kinase C theta (PKCtheta) expression and constitutive activation in gastrointestinal stromal tumors (GISTs). Cancer Res. 64:5127-5131.

77. Southwell, B.R. 2003. Localization of protein kinase $\mathrm{C}$ theta immunoreactivity to interstitial cells of Cajal in guinea-pig gastrointestinal tract. Neurogastroenterol. Motil. 15:139-147.

78. Tsujimura, T., et al. 2001. Expression of the intermediate filament nestin in gastrointestinal stromal tumors and interstitial cells of Cajal. Am. J. Pathol. 158:817-823.

79. Huizinga, J.D., et al. 1995. W/kit gene required for interstitial cells of Cajal and for intestinal pacemaker activity. Nature. 373:347-349.

80. Ward, S.M., Burns, A.J., Torihashi, S., Harney, S.C., and Sanders, K.M. 1995. Impaired development of interstitial cells and intestinal electrical rhythmicity in steel mutants. Am. J. Physiol. 269:C1577-C1585.

81. Chen, H., et al. 2002. Polyclonal nature of diffuse proliferation of interstitial cells of Cajal in patients with familial and multiple gastrointestinal stromal tumours. Gut. 51:793-796.

82. Antonescu, C.R., et al. 2004. Gene expression in gastrointestinal stromal tumors is distinguished by KIT genotype and anatomic site. Clin. Cancer Res. 10:3282-3290.

83. Subramanian, S., et al. 2004. Gastrointestinal stromal tumors (GISTs) with KIT and PDGFRA mutations have distinct gene expression profiles. Oncogene. 23:7780-7790.

84. Burdick, J.S., et al. 2000. Treatment of Ménétrier's disease with a monoclonal antibody against the epidermal growth factor receptor. N. Engl. J. Med. 343:1697-1701.

85. Settle, S.H., et al. 2005. Chronic treatment of Ménétrier's disease with Erbitux: clinical efficacy and insight into pathophysiology. Clin. Gastroenterol. Hepatol. 3:654-659.

86. Heinrich, M.C., et al. 2000. Inhibition of c-kit receptor tyrosine kinase activity by STI 571, a selective tyrosine kinase inhibitor. Blood. 96:925-932.

87. Tuveson, D.A., et al. 2001. STI571 inactivation of the gastrointestinal stromal tumor c-KIT oncoprotein: biological and clinical implications. Oncogene. 20:5054-5058.

88. Demetri, G.D., et al. 2002. Efficacy and safety of 
imatinib mesylate in advanced gastrointestinal stromal tumors. N. Engl. J. Med. 347:472-480.

89. Joensuu, H., et al. 2001. Effect of the tyrosine kinase inhibitor STI571 in a patient with a metastatic gastrointestinal stromal tumor. N. Engl. J. Med. 344:1052-1056.

90. van Oosterom, A.T., et al. 2001. Safety and efficacy of imatinib (STI571) in metastatic gastrointestinal stromal tumours: a phase I study. Lancet. 358:1421-1423.

91. Demetri, G.D. 2002. Targeting the molecular pathophysiology of gastrointestinal stromal tumors with imatinib. Mechanisms, successes, and challenges to rational drug development. Hematol. Oncol. Clin. North Am. 16:1115-1124.

92. Verweij, J., et al. 2004. Progression-free survival in gastrointestinal stromal tumours with high-dose imatinib: randomised trial. Lancet. 364:1127-1134.

93. Benjamin, R.S., et al. 2003. Phase III dose-randomized study of imatinib mesylate (STI571) for GIST Intergroup S0033 early results [abstract]. Proceedings of the American Society for Clinical Oncology. 22:814.

94. Joensuu, H., et al. 2002. Management of malignant gastrointestinal stromal tumours. Lancet Oncol. 3:655-664.

95. Savage, D.G., and Antman, K.H. 2002. Imatinib mesylate: a new oral targeted therapy. N. Engl. J. Med. 346:683-693.

96. van Oosterom, A.T., et al. 2002. Update of phase I study of imatinib (STI571) in advanced soft tissue sarcomas and gastrointestinal stromal tumors: a report of the EORTC Soft Tissue and Bone Sarcoma Group. Eur. J. Cancer. 38(Suppl. 5):S83-S87.

97. Debiec-Rychter, M., et al. 2004. Use of c-KIT/PDGFRA mutational analysis to predict the clinical response to imatinib in patients with advanced gastrointestinal stromal tumours entered on phase I and II studies of the EORTC Soft Tissue and Bone Sarcoma Group. Eur. J. Cancer. 40:689-695.

98. Heinrich, M.C., et al. 2006. Molecular correlates of imatinib resistance in gastrointestinal stromal tumors. J. Clin. Oncol. 24:4764-4774.

99. Antonescu, C.R., et al. 2005. Acquired resistance to imatinib in gastrointestinal stromal tumor occurs through secondary gene mutation. Clin. Cancer Res. 11:4182-4190.

100.Debiec-Rychter, M., et al. 2005. Mechanisms of resistance to imatinib mesylate in gastrointestinal stromal tumors and activity of the PKC412 inhibitor against imatinib-resistant mutants. Gastroenterology. 128:270-279.

101. Wardelmann, E., et al. 2006. Polyclonal evolution of multiple secondary KIT mutations in gastrointesti- nal stromal tumors under treatment with imatinib mesylate. Clin. Cancer Res. 12:1743-1749.

102.Bauer, S., Yu, L.K., Demetri, G.D., and Fletcher, J.A. 2006. Heat shock protein 90 inhibition in imatinibresistant gastrointestinal stromal tumor. Cancer Res. 66:9153-9161.

103. Prenen, H., et al. 2006. Efficacy of the kinase inhibitor SU11248 against gastrointestinal stromal tumor mutants refractory to imatinib mesylate. Clin. Cancer Res. 12:2622-2627.

104.Demetri, G.D., et al. 2006. Efficacy and safety of sunitinib in patients with advanced gastrointestinal stromal tumour after failure of imatinib: a randomised controlled trial. Lancet. 368:1329-1338.

105. Coffey, R.J., Jr., et al. 1987. Production and autoinduction of transforming growth factor-alpha in human keratinocytes. Nature. 328:817-820.

106. Barnard, J.A., et al. 1994. Auto- and cross-induction within the mammalian epidermal growth factor-related peptide family. J. Biol. Chem. 269:22817-22822.

107. Willis, R. 1989. The works of William Harvey. University of Pennsylvania Press. Philadelphia, Pennsylvania, USA. 616-617.

108.Lennartsson, J., Jelacic, T., Linnekin, D., and Shivakrupa, R. 2005. Normal and oncogenic forms of the receptor tyrosine kinase kit. Stem Cells. 23:16-43. 